\title{
Conference: ICEM05 / DECOM05
}

Track: $\quad 2.3$ or 2.5

Contact: Geoff Freeze, Sandia National Laboratories, USA

505-284-8594 (ph), 505-284-4002 (fax), gafreez@sandia.gov

\section{YUCCA MOUNTAIN FEATURE, EVENT, AND PROCESS (FEP) ANALYSIS}

Geoff Freeze, Sandia National Laboratories

A Total System Performance Assessment (TSPA) model was developed for the U.S. Department of Energy (DOE) Yucca Mountain Project (YMP) to help demonstrate compliance with applicable postclosure regulatory standards and support the License Application (LA). Two important precursors to the development of the TSPA model were (i) the identification and screening of features, events, and processes (FEPs) that might affect the Yucca Mountain disposal system (i.e., FEP analysis), and (ii) the formation of scenarios from screened in (included) FEPs to be evaluated in the TSPA model (i.e., scenario development).

YMP FEP analysis and scenario development followed a five-step process:

1. Identify a comprehensive list of FEPs potentially relevant to the long-term performance of the disposal system.

2. Screen the FEPs using specified criteria to identify those FEPs that should be included in the TSPA analysis and those that can be excluded from the analysis.

3. Form scenarios from the screened in (included) FEPs.

4. Screen the scenarios using the same criteria applied to the FEPs to identify any scenarios that can be excluded from the TSPA, as appropriate.

5. Specify the implementation of the scenarios in the computational modeling for the TSPA, and document the treatment of included FEPs.

This paper describes the FEP analysis approach (Steps 1 and 2) for YMP, with a brief discussion of scenario formation (Step 3). Details of YMP scenario development (Steps 3 and 4) and TSPA modeling (Step 5) are beyond scope of this paper.

The identification and screening of the YMP FEPs was an iterative process based on sitespecific information, design, and regulations. The process was iterative in the sense that there were multiple evaluation and feedback steps (e.g., separate preliminary, interim, and final analyses).

The initial YMP FEP list was compiled from an existing international list of FEPs from other radioactive waste disposal programs and was augmented by YMP site- and designspecific FEPs identified from project literature and other sources. The YMP FEP list then evolved through a series of TSPA iterations, through repeated iterations with subject matter experts, and in parallel with new site and design information. An electronic FEP 
database and an associated FEP classification system were developed to catalog the YMP FEPs and enhance the ability of project personnel to examine the FEPs. The formal iterations and the use of the database assisted in the demonstration of the completeness of the FEP list.

FEP screening was performed in accordance with final regulatory standards. FEPs were screened out (excluded) by either (i) low probability, (ii) low consequence, or (iii) by inconsistency with the regulations. All FEPs that could not be screened out formed the conceptual basis for, and were included in, the TSPA model.

In summary, formal YMP FEP analysis produced:

- A comprehensive and manageable list of FEPs potentially relevant to Yucca Mountain disposal system postclosure performance.

- A subset of included FEPs from which to develop TSPA scenarios and models

- An electronic database to assist project personnel and reviewers in locating FEP and model related information. 